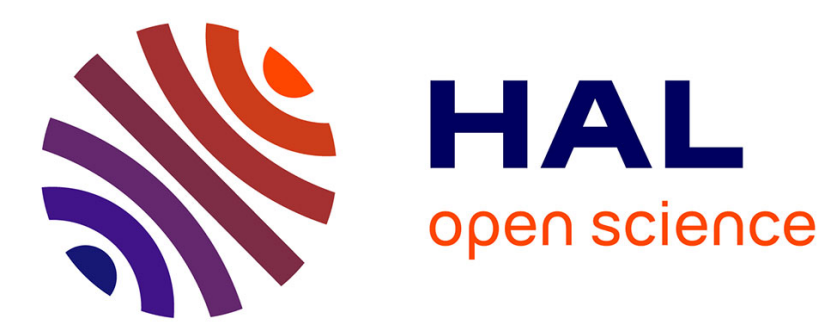

\title{
Channels of buyer influence and labor standard compliance: the case of Cambodia's garment sector Chikako Oka
}

\section{To cite this version:}

Chikako Oka. Channels of buyer influence and labor standard compliance: the case of Cambodia's garment sector. Advances in Industrial and Labor Relations, 17, pp.153-183, 2010, 10.1108/S07426186(2010)0000017008 . hal-02952274

\section{HAL Id: hal-02952274 \\ https://hal.science/hal-02952274}

Submitted on 25 Mar 2021

HAL is a multi-disciplinary open access archive for the deposit and dissemination of scientific research documents, whether they are published or not. The documents may come from teaching and research institutions in France or abroad, or from public or private research centers.
L'archive ouverte pluridisciplinaire HAL, est destinée au dépôt et à la diffusion de documents scientifiques de niveau recherche, publiés ou non, émanant des établissements d'enseignement et de recherche français ou étrangers, des laboratoires publics ou privés. 


\title{
CHANNELS OF BUYER INFLUENCE AND LABOR STANDARD COMPLIANCE: THE CASE OF CAMBODIA'S GARMENT SECTOR
}

\author{
Chikako Oka
}

\begin{abstract}
Given the continued growth in the globalization of production, working conditions in global supply chains have come under increased scrutiny. While there has been much debate about corporate codes of conduct and monitoring procedures, the question of how buyers influence their suppliers' working conditions at the factory level remains poorly understood. Using a unique data set based on monitoring by the International Labor Organization (ILO) and original survey data collected in Cambodia's garment sector, this study shows that the main channel linking buyers and supplier compliance-performance is the nature of their relationships. Market-based relationships mediated through sourcing agents are systematically associated with poorer compliance performance. In particular, when a reputation-conscious buyer is sourcing from a factory, it has a positive effect on compliance, and their presence appears to condition relationship variables. Deterrence and learning channels are not supported by the evidence. The findings signal the need to pay more attention to the nature of buyer-supplier relationships if we seek to improve labor standard compliance. Market-based relationships motivate neither buyers nor suppliers to invest their time and resources to tackle the root causes of poor working conditions. Rather, the results here indicate the need to develop collaborative relationships marked by open dialogue, trust, and commitment, which in turn help to foster an environment supportive of continuous improvement in working conditions.
\end{abstract}




\section{INTRODUCTION}

As production becomes increasingly globalized, working conditions and labor rights in global supply chains have entered the spotlight and come under increased scrutiny. In the absence of effective state regulation and a global regulatory framework, working conditions in most developing countries remain substandard. Faced with anti-sweatshop campaigns and exposure of child labor and dismal working conditions in their supply chains, many multinational enterprises (MNEs) have come to adopt codes of conduct (CoC) and monitoring procedures (Elliott \& Freeman, 2003). To a large extent, therefore, non-state regulation has become one of the dominant modes of regulating labor conditions in global supply chains.

The rise of non-state regulation has provoked heated debates about the desirability and effectiveness of $\mathrm{CoC}$ and monitoring procedures (Esbanshade, 2004; Jenkins, Pearson, \& Seyfang, 2002; Nadvi \& Waltring, 2004; Seidman, 2008). Nevertheless, the question of what determines working conditions in supplier establishments and in particular, how buyers influence them remains poorly understood. Recognizing this gap, Locke, Kochan, Romis, \& Qin (2007) call for a more comprehensive approach to understanding and addressing the root causes of poor working conditions. This paper contributes to reframing the debate by delving into how buyer-supplier relationships influence supplier compliance-performance.

The existing studies of buyer influence on supplier working conditions are predominantly case studies of branded buyers (Frenkel, 2001; Frenkel \& Scott, 2002; Locke \& Romis, 2006). They generally conclude that close and collaborative relationships between brands and suppliers encourage learning and value-sharing, contributing to better working conditions. Although insightful, these case studies are based on only a handful of suppliers. Addressing this weakness, Locke, Qin, \& Brause (2007) quantitatively assess the determinants of supplier compliance-performance using Nike's compliance data covering 830 suppliers in 51 countries. They find that factories designated as Nike's "strategic partners" and those frequently visited by Nike's staff (both compliance and production) have higher compliance scores. They see this as evidence that close supplier-buyer relationships foster trust and encourage knowledge sharing, positively influencing working conditions. Nonetheless, they assume rather than demonstrate such channels of buyer influence, while their exclusive focus on one global brand precludes generalization. 
Recently, Jiang (2009) has found a statistically significant link between the nature of buyersupplier relationships and supplier compliance with $\mathrm{CoC}$, based on survey data from China's garment industry. Jiang shows that buyer-supplier relationships characterized by open and two-way dialogue are positively related to supplier compliance with CoC. The paper, however, does not differentiate the types of buyers, which are likely to affect supplier compliance-performance. Moreover, it does not consider other channels of buyer influence such as deterrence and learning.

In an attempt to fill this knowledge gap, Oka (2009) exploits unique industry-wide panel data from Cambodia's garment sector and shows that factories supplying for reputationconscious buyers - defined according to buyers' membership status of multi-stakeholder initiatives - have better labor standard compliance than factories without this factor. This effect remains significant after controlling for factory characteristics and using different specifications. Nevertheless, data limitation prevented it from delving into the black box of buyer influence: through which channels buyers influence their supplier complianceperformance.

The purpose of this paper, therefore, is two folds: (i) to examine different channels of buyer influence with regard to supplier compliance-performance and (ii) to assess whether reputation-conscious buyers affect those channels differently. To achieve this task, the paper exploits ILO monitoring data and original survey data collected in Cambodia's garment sector. The paper proceeds as follows. The next section begins with a short description of the ILO monitoring program in Cambodia's garment sector, which is followed by the theories and hypotheses. The subsequent section discusses the data and methods, followed by estimation results. The paper then concludes with overall observations and practical implications.

\section{THE ILO MONITORING PROGRAM IN CAMBODIA'S GARMENT SECTOR}

Cambodia's garment sector has been undergoing an innovative experiment to improve working conditions. All exporting garment factories are required by the Cambodian government to submit to regular monitoring by the International Labor Organization (ILO) program called Better Factories Cambodia (BFC). In fact, this ILO monitoring program grew out of the 1999 US-Cambodia bilateral trade agreement, in which an increase in a quota (i.e. 
access to the US market) was conditioned upon significant improvements in working conditions (Polaski, 2006). The ILO was asked to monitor and report progress in the industrywide labor compliance level, which was then used by the US government to determine quota increases and subsequently by buyers for sourcing decisions (Kolben, 2004). The Cambodian government has come to see the ILO monitoring scheme as a niche strategy to attract reputation-conscious buyers while these buyers has come to appreciate ILO monitoring as a stamp of approval. This explains why the ILO monitoring program has been renewed even after the expiration of the quota regime at the end of $2004 .^{1}$

Compared to private monitoring often criticized for its ineffectiveness and conflict of interests, monitoring by the ILO enjoys important advantages. First, unlike audit firms dependent on factories they audit for revenues, ILO monitors are not directly paid by monitored factories, which helps maintain its impartiality. ${ }^{2}$ Second, unlike many commercial auditors detached from local contexts and unable to speak directly to local stakeholders, ILO monitors are locally hired Cambodian nationals who speak the language and understand the local context, increasing their sensitivity and effectiveness as monitors. Third, ILO monitors are hired through competitive procedures, extensively trained, and well-equipped, helping ensure the quality of monitoring.

The Cambodian case provides an excellent opportunity to further our understanding about the role of buyers in influencing supplier working conditions. While the ILO is mandated to monitor and report factory compliance with the Cambodian labor law and international labor standards, the ILO has no enforcement power. The Ministry in charge of labor inspection and remediation suffers from incapacity and corruption, which prevents it from effectively enforcing the labor law. Consequently, buyers often act as a virtual enforcement authority, demanding corrective action from suppliers when important violations are found. Furthermore, ILO-BFC has provided the author with the industry-wide monitoring and other factory-level data as well as logistical support to conduct a specific survey targeting garment factory managers. The survey was critical to obtaining detailed information on how suppliers interact with buyers.

\section{THEORIES AND HYPOTHESES}

This section discusses the theories that link buyer variables and supplier complianceperformance. Three potential channels of buyer influence are examined: deterrence, 
relationship, and learning. Each of the three channels generates three hypotheses: that a) the channel is directly linked to supplier compliance-performance, b) the channel mediates the effect of reputation-conscious buyers on supplier compliance-performance, and c) the channel interacts with reputation-conscious buyers and influences supplier complianceperformance.

\section{Deterrence}

In economic and legal studies, the traditional view of compliance behavior has emphasized deterrence, assuming that rational and profit maximizing firms decide to comply with regulation only when the expected cost of non-compliance exceeds the expected benefit (Becker, 1968; Stigler, 1970). This theory posits that a firm's propensity to comply with regulations is positively related to the probability of detection and the expected penalty of violation. This deterrence theory has been applied to occupational safety and health (Viscusi, 1979), minimum wage compliance (Ashenfelter \& Smith, 1979), and recently, to private monitoring of minimum wage in the US garment industry (Weil, 2005; Weil \& Mallo, 2007). They find that more stringent forms of monitoring by manufacturers are associated with better contractor compliance with minimum wage regulations.

Regarding reputation-conscious buyers, the deterrence theory would predict that those buyers who face a higher probability of detection and expected penalties for poor working conditions in their supply chains are more likely to rigorously regulate their suppliers than other buyers. Some buyers, predominantly global brands, have been repeatedly exposed by the media and criticized by labor activists. Moreover, the expected penalty is higher for those buyers that derive much of their value from their brand image, which could be easily damaged by sweatshop allegations (Conroy, 2007).

\section{Detection Hypotheses}

According to the deterrence theory, suppliers who are rigorously monitored and credibly sanctioned by buyers are likely to expect a higher cost of non-compliance, leading them to reduce non-compliance. The probability of detection is higher when buyers' compliance staff visits supplier establishments frequently.

Hypothesis 1-a. The frequency of visits by buyers' compliance staff is negatively related to supplier non-compliance. 
Reputation-conscious buyers may affect their supplier compliance-performance through factory visits in two ways. First, the frequency of visits may be different. Given the higher stakes, reputation-conscious buyers may visit their suppliers more often than other buyers, which may explain why reputation-conscious buyers are associated with better supplier compliance-performance.

Hypothesis 1-b. The effect of reputation-conscious buyers on supplier non-compliance is mediated by the frequency of visits.

Alternatively, the frequency of visits by reputation-conscious buyers may not be different, but the impact of their visits may be different from other buyers if the 'quality' of their visits is higher. In this case, it is not the frequency of compliance visits per se, but the interaction of visit frequency and reputation-conscious buyers that influences supplier complianceperformance.

Hypothesis 1-c. The negative association between the frequency of visits and noncompliance is more pronounced in the presence of reputation-conscious buyers.

\section{Warning Hypotheses}

The other element in the deterrence theory is the expected penalty of non-compliance. For suppliers, a potential penalty of non-compliance is a cancellation of orders by buyers. When a buyer and a supplier sign a contract, it normally includes a clause that obliges suppliers to abide by the buyer's CoC. Although it occurs only rarely, buyers have the right to terminate the contract in the case of non-compliance. Hence, buyers who want to rigorously enforce their $\mathrm{CoC}$ are likely to communicate the negative consequence of non-compliance (i.e. cancellation of orders) by warning their suppliers implicitly or explicitly. In turn, suppliers who receive such warnings are likely to take compliance issues more seriously.

Hypothesis 2-a. Warnings by buyers about the negative consequence of non-compliance are negatively related to supplier non-compliance.

As discussed above, reputation-conscious buyers with higher stakes in regulating labor conditions in their supply chains may influence their suppliers through warnings in two ways. 
First, they may be more likely to issue warnings than other buyers, which may help reduce non-compliance.

Hypothesis 2-b. The effect of reputation-conscious buyers on supplier non-compliance is mediated by warnings.

Alternatively, it may not be whether or not a warning has been issued, but rather who issues the warning that makes a difference for supplier compliance-performance. When a reputation-conscious buyer issues a warning, it may be taken more seriously by suppliers, given the higher stakes involved.

Hypothesis 2-c. The negative association between warnings and supplier non-compliance is more pronounced in the presence of reputation-conscious buyers.

\section{Buyer-Supplier Relationships}

The management literature on supplier behavior has focused on opportunism and the nature of buyer-supplier relationships. The literature principally draws on transaction cost economics (TCE) and relational exchange theory (RET), which have been integrated in many studies investigating buyer-supplier relationships and their impacts (Heide \& John, 1992; Jiang, 2009; Morgan \& Hunt, 1994).

\section{Transaction Cost Economics (TCE)}

The TCE approach is based on the behavioral assumptions of bounded rationality and opportunism (Williamson, 1985). Unlike the deterrence theory that assumes perfectly rational individuals, TCE (and more broadly new institutional economics) assumes that individuals are intendedly rational but constrained by limited capacity to gather and process information (Simon, 1957). Opportunism refers to a lack of honesty in transaction, which can be active, such as lying, stealing, and cheating or passive, including subtle forms of deceit such as withholding of information (Williamson, 1985). More broadly, behaviors that are inconsistent with an agreed contract or principle are considered opportunistic (Wathne \& Heide, 2000). From the TCE perspective, therefore, non-compliance with agreed CoC can be viewed as suppliers' opportunistic behavior vis-à-vis buyers. 
According to Williamson's logic, the degree of opportunism largely depends on asset specificity, in the sense of a non-transferable investment in one's partner. When a buyer invests time and resources in its supplier, this investment cannot be redeployed elsewhere, and vice versa. A higher degree of asset specificity required in transaction, then, raises switching costs and induces commitment and reduces opportunism from the party that made such investment. The early TCE literature emphasized vertical integration, or hierarchy, as a solution to opportunism given its superior capacity to monitor and align incentives than market (Williamson, 1975). Nonetheless, over the past decades, new organizational forms that are neither market nor hierarchy, or hybrids, have become more dominant (Williamson, 1991). Under the hybrid form of governance, the cost of replacing a partner is more expensive than market and thus parties work together to restrain opportunism (Joshi \& Stump, 1999). Opportunism is often controlled through "learning by monitoring" characterized by collaboration and information exchanges (Helper, MacDuffie, \& Sabel, 2000).

\section{Relational Exchange Theory (RET)}

A legal theorist Macneil (1980)'s concept of relational contract, in which social relations shaped by prevailing norms and values are embedded in contracts, has been extensively applied to buyer-supplier relationships. Unlike the TCE approach that sees each transaction as a unit of analysis, the RET views the relationship based on the transactions as a unit of analysis (Vandaele, Rangarajan, Gemmel, \& Lievens, 2007). While the RET does not reject the existence of opportunism, it rejects the assumption of universal opportunism (Hawkins, Wittman, \& Beyerlein, 2008). Parties to relational exchange depend on relational norms such as trust and commitment broadly defined as the mutual expectations that exchange partners will act in mutually beneficial ways. Hence, opportunistic behavior in relational exchange is controlled through mutual and self-regulation rather than threats or incentives (Gundlach, Achrol, \& Mentzer, 1995).

Given their relative strengths, most scholars combine the TCE and RET to explain buyersupplier relationships and related performance. For instance, Sako (1992) distinguishes two types of contracting relationships: arm's-length versus obligational contractual relations. Arm's-length contracting is a transaction-based relationship where tasks, duties, and conditions are spelled out in explicit contracts. Obligation contracting, on the other hand, is a trust-based relationship characterized by a high level of interdependence, risk sharing, and long term horizons. Each type of relationships involves a trade-off. While buyers pursuing the arm's-length strategy may be able to obtain the lowest price by playing one supplier off 
against another, they have more difficulty in inducing commitment and controlling opportunism. In contrast, parties to the obligational contracting can reduce uncertainty and opportunism through developing trust and frequent communication, but they are locked in the relationship.

Empirical support for the importance of buyer-supplier relationships in influencing supplier compliance-performance is growing. Through a matched-pair case study, Frenkel \& Scott (2002) examine two otherwise similar Adidas suppliers and explain the gap in working conditions by their varying relationships with Adidas: one enjoyed a close relationship while the other was kept at arms' length. Jiang (2009) shows that norm-based relationships characterized by open, two-way dialogue and joint problem solving are positively associated with supplier compliance with $\mathrm{CoC}$.

\section{Long-term Relationship Hypotheses}

From the TCE perspective, long-term relationships tend to justify idiosyncratic investment because parties have long enough horizons to reap the benefits of their investment. Also, repetitive interactions provide opportunities to reward good behavior and punish opportunism. From the RET viewpoint, the duration of relationships helps fosters trust and align firms expectations, reducing opportunistic behavior. Empirically, long-term relationships are found to increase commitment and reduce opportunism in inter-firm relationships (Joshi \& Stump, 1999). Hence, the longer duration of the relationship, especially with the most important buyer, is likely to reduce supplier non-compliance.

Hypothesis 3-a. The duration of the relationship with a supplier's most important buyer is negatively related to supplier non-compliance.

Reputation-conscious buyers seek to ensure that their supply chains are constantly up to a high standard in terms of quality and compliance, which requires a higher degree of asset specificity. Accordingly, reputation-conscious buyers are likely to prefer a long-term relationship to foster trust and induce cooperation. This tendency may explain why suppliers of reputation-conscious buyers are associated with better compliance-performance.

Hypothesis 3-b. The effect of reputation-conscious buyers on supplier non-compliance is mediated by the duration of the relationship with a supplier's most important buyer. 
While a long-term relationship may be necessary to induce better compliance, it may not be sufficient if it is conditioned upon the type of buyers: reputation-conscious buyers are more likely to make idiosyncratic investment in their suppliers than other buyers. In other words, the duration of the relationship may significantly affect supplier compliance only when it is with a reputation-conscious buyer.

Hypothesis 3-c. The negative association between the duration of the relationship and supplier non-compliance is more pronounced in the presence of reputation-conscious buyers.

\section{Market-based Relationship Hypotheses}

According to the TCE, market-based, arm's-length relationships are preferred when the degree of asset specificity required in transactions is low because it is more efficient to use the market to manage standardized transactions than to make idiosyncratic investment in their partners. While efficiency may be attained in a market-based relationship, controlling opportunism is more difficult given the lower switching costs despite safeguards such as threats and incentives. From the RET perspective, the lack of relational norms in a marketbased relationship precludes fostering commitment and trust. In sum, both the TCE and RET predict a higher degree of opportunism under market-based relationships.

In the global garment industry, three types of buyer-supplier relationships exist. The first type goes through sourcing agents, which match buyers with factories around the world, searching for the best combination of price, quality, and delivery demanded by buyers. Agents function as a "one-stop shop" or a supply chain manager, and the relationship between a buyer and a supplier factory is a contract-based one-off relationship (Play Fair, 2008). The second type goes through vendors, which are MNEs with multiple production facilities. Vendors tend to have long and established relationships with buyers and distribute orders to their subsidiaries around the globe as well as to sub-contractors. The third type is a direct relationship between a buyer and a factory, which could occur when a factory or its head office enjoys a long and established relationship with its buyer. In sum, the first type represents a market-based relationship, which is likely to be associated with worse compliance-performance.

Hypothesis 4-a. Market-based relationships through agents are positively related to supplier non-compliance. 
On the other hand, reputation-conscious buyers who are demanding about quality and compliance standards are likely to avoid market-based relationships that do not encourage suppliers to commit to continuous improvement. In this case, reputation-conscious buyers are associated with better supplier compliance-performance precisely because they avoid such relationships.

Hypothesis 4-b. The effect of reputation-conscious buyers on supplier non-compliance is mediated by the absence of market-based relationships.

Alternatively, even when transacting through agents, reputation-conscious buyers may still make idiosyncratic investment and induce supplier efforts in a way that other buyers do not. In this case, the negative effect of market-based relationships is mitigated by the presence of reputation-conscious buyers.

Hypothesis 4-c. The positive association between market-based relationships and supplier non-compliance is less pronounced in the presence of reputation-conscious buyers.

\section{Learning Hypotheses}

The nature of buyer-supplier relationships also affects the degree of learning, which influences working conditions in supplier establishments. Technical assistance and knowledge spillovers from buyers signal buyers' credible commitment to the relationship, which then helps foster trust between buyers and suppliers (Sako \& Helper, 1998; Bönte, 2008). While providing learning opportunities do not necessarily provide protection against supplier opportunism, it may help suppliers to improve production processes and work organization, which may in turn improve working conditions.

Case studies have found that there is substantial scope for learning between buyers and suppliers that helps improve working conditions. In a matched-pair case study, Locke \& Romis (2006) illustrate how a collaborative relationship between Nike and its supplier encouraged upgrading of a production system and work organization, leading to higher wage levels and shorter work hours. Specifically, the supplier that adopted a lean-production system with the help of Nike benefited from greater worker participation and higher productivity. Hence, it can be hypothesized that the more learning opportunities buyers provide, the better the supplier compliance-performance. 
Hypothesis 5-a. Learning opportunities provided by buyers are negatively related to supplier non-compliance.

Nonetheless, not all buyers provide similar learning opportunities. As the case studies of global brands corroborate, brands tend to provide more extensive training and assistance to upgrade their supplier production systems and to improve quality control than other buyers. Such asset specific investment is justified by high quality and compliance standards sought by reputation-conscious buyers. Therefore, reputation-conscious buyers may provide more learning opportunities than others, helping reduce supplier non-compliance.

Hypothesis 5-b. The effect of reputation-conscious buyers on supplier non-compliance is mediated by learning opportunities.

Alternatively, it may be the 'quality' of learning rather than the quantity of learning that affects supplier compliance-performance. Reputation-conscious buyers may provide 'better' learning opportunities than other buyers, given the higher standards required.

Hypothesis 5-c. The negative association between learning opportunities and supplier noncompliance is more pronounced in the presence of reputation-conscious buyers.

\section{DATA AND METHODS}

This study exploits monitoring and firm characteristics data collected by ILO-BFC. ILO monitors conduct un-announced visits of all the exporting garment factories every 8 months on average. ILO monitoring covers the entire population of exporting factories in Cambodia (approximately 300) and the data are systematically available since 2006. Nevertheless, ILOBFC does not collect detailed information on buyer-supplier relationships, which is critical to test the above hypotheses. For this reason, the author conducted a survey of supplier factories in the Cambodian garment industry in the latter half of 2008. Consequently, the size of the survey determines the size of the sample.

Survey Data Collection 
The survey was conducted between June and October 2008 in Phnom Penh, Cambodia, and the survey targeted general managers of exporting garment factories. A total of 51 factory managers responded to the survey out of approximately 300 of Cambodia's export garment factories. ${ }^{3}$ While it covers only 17 percent of the industry population, it does not indicate the response rate as explained below. Survey questions have been tested with industry experts and then piloted in four factories. Given that factory managers are predominantly Chinese speakers, the questionnaire and the cover letter were written in both English and Chinese.

The survey collection employed a multi-pronged approach to increase responses given limited time and resources. First, ILO monitors distributed and collected questionnaires during their routine factory visits. Second, the author accompanied ILO monitors and conducted face-to-face interviews with factory managers during factory visits. Third, the author sent emails to factory mangers asking to complete the questionnaire on-line. The three survey vehicles were used equally: monitors collected 16 responses, the author interviewed 17 factory managers, and the web-based survey collected 18 responses.

The major issue in survey is a problem of non-response, which introduces bias and distorts the representativity of a sample. For this reason, Hansen \& Hurwitz (2004) propose combining interviews and mail questionnaires to optimize the response rate given resource constraints. Indeed, interviews helped alleviate non-response problems pervasive in selfcompleted survey collection. When managers were present, which was almost always the case, the interview approach attained a 100 percent response rate (i.e. all managers agreed to be interviewed) while the response rate for the web-based approach reached only 15.5 percent. ${ }^{4}$ As ILO monitoring schedule is random (i.e. not affected by the level of compliance or any other explanatory variables), interviewing during factory visits reduces potential bias in the sample. Thanks to the multi-pronged survey collection approach, the sample profile is broadly in line with the population profile as shown in Table 1, although larger factories and better performers are slightly over-represented. ${ }^{5}$

\section{Measures and Descriptive Statistics}

\section{Dependent Variable: Non-Compliance}

ILO monitors assess over 300 checklist items of labor standards, which are based on the Cambodian labor law and the international labor standards. The monitored standards have been agreed by the Cambodian government, employers, and unions in the garment industry. The checklist items are grouped into the following categories: contracts, wages, hours, leave, 
welfare, occupational safety and health $(\mathrm{OSH})$, and fundamental rights. ${ }^{6}$ As for monitoring procedures, un-announced visits span an entire day or longer for larger establishments. The process includes an on-site inspection, meetings with human resource managers, union leaders, and shop stewards as well as off-site interviews with workers. Copies of pay slips and hour records are collected for verification. ILO monitors assess each checklist item and determine whether a factory complies with a specified standard. When the factory is deemed out of compliance with a certain item, monitors make a standardized suggestion for improvement. Therefore, the presence of a suggestion is equivalent to non-compliance and the absence of a suggestion, compliance. In general, a smaller number of suggestions or noncompliance items indicates better working conditions.

The industry-average compliance level in 2008 was 90 percent (where a score of 100 indicates full compliance), suggesting a very high level of overall compliance in the Cambodian garment industry. In fact, giving equal weight to each checklist item leads to over-representation of $\mathrm{OSH}$ and welfare, as together they account for $35.7 \%$ of the total checklist items. $^{7}$ To rectify this over-representation, the weight of each OSH/welfare item has been reduced to half, leading to a better balance of issue categories in the composite: contract (15.4\%), wage (24.6\%), hours/leave (19.7\%), welfare/OSH (21.5\%), and fundamental rights $(18.6 \%)^{8}$

\section{Independent Variables}

Independent variables can be loosely organized under the categories articulated in the hypotheses section; namely, those of deterrence, buyer-supplier relationships, learning, and the reputation-conscious buyer. Table 2 shows the survey responses regarding the channels of buyer influence.

\section{Deterrence}

One of the measures of deterrence is the frequency of visits by buyers' compliance staff. As shown in Table 2, there is large variation: 60 percent of factories receive up to 5 compliance visits per year while 22 percent receive 15 times or more. The frequency of visits is coded from 1 to 6 as an interval measure. The other measure of deterrence is a dummy variable of whether or not buyers have warned implicitly or explicitly about the consequence of noncompliance (i.e. cancellation of orders). 46 percent of the managers acknowledge having received implicit or explicit warnings. ${ }^{9}$ 
There is a potential issue of endogeneity with the deterrence variables if buyers tend to visit problematic factories and issue warnings disproportionately to these factories. While endogeneity may be controlled by using instrumental variables or first-differencing variables, a lack of appropriate instruments and temporal gaps between dependent and independent variables preclude using these techniques. Nonetheless, potential endogeneity may be less problematic considering that buyer compliance visits have multiple purposes unlike ILO monitoring. Locke, Qin, \& Brause (2007:18) mention that Nike concentrates its resources on high-risk factories and suppliers with which they want to develop more long-term relationships. Similarly, the author's interviews with buyer local representatives find that they visit their suppliers not just to enforce their $\mathrm{CoC}$, but to develop open and close relationships. Moreover, the problem of endogeneity for warnings may be less severe since the author's interviews have found that supplier perception of warnings varies considerably. Some managers considered accepting buyer $\mathrm{CoC}$ as equivalent to an implicit warning given the clause in $\mathrm{CoC}$ stipulating that violation of $\mathrm{CoC}$ may lead to termination of contracts. Other managers, however, considered warnings as specific buyer remarks addressing particular compliance problems.

\section{Buyer-Supplier Relationships}

The nature of the buyer-supplier relationships is measured by the duration of the relationship with a supplier's most important buyer and the mode of communication with buyers. The duration varies from $0-2$ years (14 percent) to 10 years or more (16 percent), while the majority falls between 3 and 6 years (54 percent). The duration of the relationship is coded from 1 to 6 as an interval measure. The mode of communication with buyers is divided quite equally: directly with buyers (43 percent), through vendors (37 percent), and through agents (31 percent). The measure of a market-based relationship is a dummy variable of whether or not a supplier communicates through agents.

\section{Learning}

According to the surveyed managers, buyers share technical knowledge often (33 percent) or sometimes (53 percent). The kind of knowledge commonly shared is quality control (95 percent), followed by work place skills ( 51 percent), and production system (40 percent). 26 percent of the surveyed factories had buyers involved to determine their production systems. Buyers encourage training often (30 percent) or sometimes (50 percent). In general, there appears to be knowledge sharing between buyers and suppliers. From these questionnaire 
responses, three dummy variables have been created to measure learning opportunities: whether or not buyers often share technical knowledge, whether or not buyers have been involved in determining production systems, and whether or not buyers often encourage training.

\section{Reputation-conscious Buyers}

The last independent variable is a reputation-conscious buyer, which may be mediated by the other independent variables or interact with them to influence compliance performance. To operationalize the concept of a reputation-conscious buyer, this paper follows Oka (2009) and looks at whether or not a buyer participates in multi-stakeholder initiatives (MSI). Drawing on O'Rourke (2006: 899), this paper defines MSI in labor regulation as a scheme that involves various stakeholders (not only companies but also non-governmental organizations) in negotiating labor standards, monitoring compliance with these standards, and establishing mechanisms to encourage firms to comply with these standards. Since reputation-conscious buyers tend to participate in MSI to show their commitment to better working conditions and safeguard their reputation, it is a reasonable proxy.

While MSI can take various forms from certification of production facilities, compliantbased investigation, to collaboration of buyers, this study focuses on the Fair Labor Association (FLA) and the Ethical Trading Initiative (ETI), given their prominence and buyer-oriented nature. ${ }^{10}$ ILO-BFC has information regarding which buyer asks for access to ILO monitoring reports for which factory, which helps identify which buyer is sourcing from which factory. Based on this information, a dummy variable of whether or not a buyer participates in the FLA or the ETI has been created (hereafter, MSI buyers).

\section{Control Variables}

The buyer-related variables are unlikely to be the only factors that affect factory-level compliance. Various establishment-level characteristics are clearly related to working conditions, and thus need to be controlled for.

First, the size of the factory, as measured by number of employees, may affect the level of labor standard compliance. Larger factories have made larger investment, raising their opportunity costs of exit, which, in turn, justifies larger investment to comply with labor standards. In particular, when achieving compliance requires large fixed costs (e.g. setting up facilities, buying equipments, training), a minimum efficiency scale may be required. 
Moreover, given that size increases employee alienation and supervisory costs, larger establishments are more likely to see the benefit of respecting labor standards to raise selfmotivation and to minimize sources of disputes (Bryson et al., 2007). For all these reasons, larger establishments are more likely to be associated with better compliance. The natural logarithm of total number of employees measures the size of the factory.

Second, the age of the establishment is likely to influence the level of compliance. Factories may learn the benefit of compliance (or the cost of non-compliance) and best practices through own experience (age). On the other hand, age may impose physical constraints: older establishments tend to have older facilities and limited space, making it more difficult and costly to comply with certain standards concerning welfare as well as safety and health (Bryson et al., 2007). As the precise data on age is not available, this study uses the total number of visits by ILO monitors since 2001, which is a reasonable proxy given that ILO monitors have visited all the exporting factories at a regular interval.

Third, firms may need to have a certain level of financial capacity to improve compliance performance (Winter \& May, 2001). As the direct measure of financial capacity is difficult to obtain, the survey asked whether the factory provides Free-on-Board (FOB) services or Cut, Make and Trim (CMT) only. FOB is a full-package service, responsible for purchase of fabric and accessories, production, and transport until loading merchandises onto the export carrier. CMT literally refers to the production process only. The distinction between the two types of services is important because sourcing of fabric and financing import and export costs require substantial resources and managerial know-how unlike CMT (USAID 2007). Hence, a dummy variable for FOB is used as a measure of financial capacity.

Financial and managerial capacity of factory can also be affected by firm network, which includes parent companies and other branches (Erikson \& Jacoby, 2003). They can provide access to capital, managerial know-how and best practices. Independent firms deprived of such access are likely to have lower capacity than networked firms. The questionnaire asked whether the factory is independent, subsidiary of a group and/or one of multiple branches in Cambodia. Thus, the dummy variable of independent firm is used to measure the absence of firm network.

Table 3 reports the descriptive statistics and inter-correlations of all the variables under investigation. A cursory examination shows statistically significant relationships between supplier non-compliance and agent, MSI-buyer, and factory size variables, which need to be further evaluated by multi-variate regressions. 
Given the small sample size, simultaneously incorporating all the independent and control variables as well as interaction terms depletes degrees of freedom. To circumvent this problem, regression analysis is conducted in two steps. First, baseline OLS regressions are run for each category of independent variables, including MSI buyer and its interaction terms. Second, an OLS regression is run with those significant predictors identified in the baseline regressions, together with control variables.

The baseline regression for deterrence:

Non-compliance $=\alpha+\beta_{1} \cdot$ visit frequency $+\beta_{2} \cdot$ warning $+\beta_{3} \cdot$ MSI buyer $+\beta_{4} \cdot$ frequency . MSI buyer $+\beta_{5} \cdot$ warning $\cdot$ MSI buyer $+\varepsilon$

The baseline regression for relationship:

Non-compliance $=\alpha+\beta_{1} \cdot$ duration of relationship $+\beta_{2} \cdot$ agents $+\beta_{3} \cdot$ MSI buyer $+\beta_{4}$. duration $\cdot$ MSI buyer $+\beta_{5} \cdot$ agents $\cdot$ MSI buyer $+\varepsilon$

The baseline regression for learning:

Non-compliance $=\alpha+\beta_{1} \cdot$ share knowledge $+\beta_{2} \cdot$ production system $+\beta_{3} \cdot$ encourage training $+\beta_{4} \cdot$ MSI buyer $+\beta_{5} \cdot$ knowledge $\cdot$ MSI buyer $+\beta_{6} \cdot$ system $\cdot$ MSI buyer $+\beta_{7} \cdot$ training $\cdot$ MSI buyer $+\varepsilon$

The main regression with added control variables:

Non-compliance $=\alpha+\beta_{1} \cdot$ significant deterrence variable $+\beta_{2} \cdot$ significant relationship variable $+\beta_{3} \cdot$ significant learning variable $+\beta_{4} \cdot$ MSI buyer $+\beta_{5} \cdot$ factory size $+\beta_{6} \cdot$ factory age $+\beta_{7} \cdot \mathrm{FOB}+\beta_{8} \cdot$ independent $+\varepsilon$

\section{RESULTS}

Baseline Regressions 
Table 4 shows the result for the deterrence model. Neither visit frequency nor warning is significantly associated with non-compliance although they both have negative signs as expected. The presence of MSI buyers is statistically significant in Model 1 and it reduces non-compliance by 7 items $(\mathrm{p}<0.05)$. This suggests that reputation-conscious buyers influence supplier compliance through a channel other than deterrence. When interaction terms are introduced in Model 2, none reaches statistical significance. Visit frequency by non-MSI buyers is negatively associated with non-compliance, and in the presence of MSI buyers, this negative effect is reinforced. Warnings by non-MSI buyers are negatively associated with non-compliance although this negative effect is reduced when MSI buyers are present. In sum, even though the direction of effects is broadly in line with the stated hypotheses, none of the deterrence hypotheses are statistically significant in the estimation results.

Table 5 shows the relationship model results, in which transaction through agents increases non-compliance by 5.7 items $(\mathrm{P}<0.05)$ in Model 3. The presence of MSI buyers is equally significant though in the opposite direction, reducing non-compliance by 5.6 items. The duration of relationship is not significant and positively associated with non-compliance. Once the variable is interacted with MSI-buyer, however, it gains significance and reduces non-compliance as shown in Model 4. ${ }^{11}$ In contrast, the duration of the relationship with a non-MSI buyer is not significant and positively related to non-compliance. This suggests that the duration of relationship helps reduce non-compliance only when the most important buyer is an MSI buyer, rejecting the general hypothesis of long-term relationships and confirming the interaction hypothesis with reputation-conscious buyers.

In Model 4, variable "Agents" measures the effect of agents in the absence of MSI buyers, and it is highly significant, increasing the number of non-compliance by 9.8 items $(p<0.01)$. This is because the agent effect for an MSI buyer has been separated by adding an interaction variable (Agents*MSI buyer), which has quite a different though non-significant effect, increasing non-compliance by only 1.4 items. ${ }^{12}$ It is interesting to note that the significance of MSI buyer is lost once the interaction terms are included. The findings generally support the market-based relationship hypothesis that transaction through agents is associated with a higher level of non-compliance. The effect of reputation-conscious buyers is partially mediated by the agent variable, but it also appears to interact with agents, implying the particularities of reputation-conscious buyers. 
In the learning model in Table 6, none of the independent variables except MSI buyer are significantly associated with non-compliance. Buyers' sharing knowledge and involvement in determining production systems have expected negative signs while encouraging training has a positive sign, possibly due to a high correlation with MSI buyer (i.e. 0.53). Running separate regressions for each independent variable renders none of them significant. None of the interaction terms are significant, suggesting that reputation-conscious buyers do not condition the effect of learning variables on non-compliance. Overall, the learning hypotheses are not supported by the estimation results.

\section{Main Regressions with Added Controls}

Table 7 reports the results of main OLS regressions with the variables found significant in the baseline regressions (i.e. relationship and reputation-conscious buyer variables) and control variables. Model 7 includes all the variables, while Model 8 displays only the significant variables without interaction terms, which more parsimonious. It shows that about onequarter of the variation in non-compliance is explained by only two variables: transaction through agents and the size of the factory.

The most consistent and significant predictor of non-compliance turns out to be the agent variable. Model 7 shows the conditional effect of agents: transacting through agents when MSI buyers are not present increases non-compliance by 10 items $(\mathrm{p}<0.01)$. Model 8 shows the general effect of agents: when a supplier transacts through agents, regardless of the presence of MSI buyers, non-compliance increases by 6.5 items $(\mathrm{p}<0.05)$. The duration of the relationship with an MSI buyer is negatively related with non-compliance and slightly significant $(\mathrm{p}<0.1)$, suggesting that MSI buyers may be qualitatively different from other buyers in their approach to buyer-supplier relationships.

As for control variables, the size of the factory is the only significant one. Larger factories tend to have fewer non-compliance as expected (e.g. a one percent increase in the number of employees reduces non-compliance by 4.3 items). The significance of MSI buyer is lost once agents and factory size are included. Other firm characteristics such as age, FOB, independence are not significant.

Interpretation of Results 
The above findings lend support to the relationship hypothesis that the nature of buyersupplier relationships importantly affects supplier compliance-performance. Specifically, market-based transactions through sourcing agents are consistently associated with poorer compliance performance across different specifications. This negative agent effect is augmented in the absence of reputation-conscious buyers. The significant effect of MSI buyer is likely to be mediated through their preference for close and established relationships with suppliers as very few MSI buyers use agents (i.e. only 3 out of 49 suppliers in the sample produce for at least one MSI buyer and use agents).

On the other hand, the duration of the relationship is found to reduce non-compliance only with an MSI buyer. This conditional effect also attests to the particularity of MSI buyers. While a long-term relationship may be a necessary condition for fostering trust and developing collaboration, it is unlikely to be a sufficient one, which explains the variable's non-significance in the main regression. With a better measure, the collaboration hypothesis is likely to be supported. ${ }^{13}$ In summary, it is likely that the absence of agents and the presence of collaboration underlie the negative and significant association between reputation-conscious buyers and supplier non-compliance found in Oka (2009).

Although the learning hypotheses are not supported by the evidence, this channel should be further explored with a larger sample and different measures of learning. As the type of relationship is likely to affect the degree of learning between buyers and suppliers, a structural model may be used. As for deterrence, there is little evidence to support the deterrence hypotheses, which may suggest that a policing approach through intensive monitoring and credible threats may not be the most effective strategy to improve supplier compliance. Nevertheless, the measures of deterrence may suffer from endogeneity, and therefore, the result is more tentative than conclusive.

Based on these findings, Figure 1 depicts a model of buyer influence on supplier compliance-performance. Given the need to maintain high standards, which require a higher degree of asset specificity, reputation-conscious buyers normally opt for direct relationships with vendors and factories. Theses buyers tend to form collaborative relationships and invest their time and resources in suppliers, encouraging supplier commitment. In contrast, other buyers, especially cost-conscious ones who specialize in more standardized products prefer market-based transactions through agents for efficiency reasons. However, market-based transactions encourage neither buyers nor suppliers to invest in their relationships. Buyers and suppliers in market-based relationships are likely to have shorter time horizons than their counterparts in collaborative relationships. Consequently, the former is less motivated to 
make asset-specific investment and commitment, which negatively affects supplier compliance-performance. Supplier compliance is also affected by the size of the factory; larger factories tend to have better compliance levels than smaller ones, given their economies of scale and higher opportunity/monitoring costs.

\section{CONCLUSION}

The rise of non-state regulation of labor standards has provoked heated debates about whether and how one can design and implement effective non-state regulatory schemes. While much has been studied and debated about $\mathrm{CoC}$ and monitoring procedures, how buyers influence working conditions in their supply chains remains poorly understood. In particular, a quantitative investigation into different channels of buyer influence has been lacking. This paper has attempted to fill the gap by examining different channels (i.e. deterrence, relationship, and learning) through which buyers influence supplier compliance-performance. Also, this study has sought to assess how reputation-conscious buyers may affect those channels differently and affect supplier compliance-performance. To accomplish theses tasks, this study has benefited from the data and logistical support provided by the ILO monitoring program in Cambodia, Better Factories Cambodia (BFC).

Based on the monitoring and survey data from the Cambodian garment factories, this paper has shown that the main channel linking buyers and supplier compliance-performance is the nature of their relationships. Suppliers who transact principally through agents systematically have a larger number of non-compliance items than suppliers who do not depend on agents. In other words, market-based relationships are associated with poorer compliance performance. On the other hand, deterrence and learning variables generally have expected signs but do not reach significance.

The findings have important practical implications. The results indicate that market-based relationships through agents may be part of the problem rather than a solution from the viewpoint of improving working conditions. Market-based relationships characterized by short-term horizons motivate neither buyers nor suppliers to invest their time and resources to understand the root causes of poor working conditions and to commit to continuous improvement. Rather, market-based relationships prompt suppliers to pass compliance audits with minimum efforts. Moreover, the non-significance of the deterrence variables suggests that a policing approach based on intensive monitoring and credible threats may not be the 
best way to bring about progress in supplier compliance. These, together, point to the limit of arm's-length, compliance-oriented relationships, which could breed mistrust and dishonesty.

Conversely, the findings signal the need to develop collaborative relationships marked by open dialogue, trust, and commitment, which helps foster an environment supportive of continuous improvement. Close and open relationships with buyers enable suppliers to discuss problems and find solutions rather than to hide them from buyers. To improve supplier working conditions, therefore, buyers need to place more importance on the quality of their relationships with suppliers-openness, trust, mutual commitment — and not just on the traditional concerns of price, quality and delivery of goods. These points are echoed by other scholars (Jiang, 2009; Locke \& Romis, 2006; Locke et al., 2007).

Such collaborative relationships may well underline the significant and positive effect of reputation-conscious buyers on supplier compliance-performance. Given the high degree of asset specificity required, reputation-conscious buyers tend to avoid market-based relationships and to form collaborative relationships with their suppliers. In fact, the duration of the relationship has a positive effect on compliance performance only with a reputationconscious buyer. In contrast, more cost-conscious buyers retailing highly standardized products tend to prefer market-based relationships which do not require asset specific investment. This suggests that attracting reputation-conscious buyers could bring important benefits not only in terms of upgrading products and processes but also in terms of forming collaborative relationships and improving working conditions.

Nevertheless, it is important to acknowledge the negative effects buyers-including reputation-conscious ones - can have on working conditions in supply chains. In fact, purchasing practices of buyers sometimes contradict with the goal of improving working conditions (CCC, 2009; Oxfam, 2004). In recent years, intense competition and rising prices have squeezed garment producer profits, making it difficult to invest in better working conditions or raise wages. On the other hand, buyers are increasingly demanding quicker delivery, which disrupts work schedules and increases overtime. Moreover, significant fluctuations in orders leave workers idol during low seasons, making it costly for factories. These buying practices have negative consequences on suppliers' capacity to improve working conditions, and thus need to be addressed.

This research has several limitations. First, the sample size is small although the sample is broadly representative of the population. Second, the deterrence variables potentially suffer from endogeneity, which needs to be better controlled in the future work. Third, while interactions and mediation between reputation-conscious buyers and other independent 
variables have been considered, relationships among the latter have not been taken into account, which may require simultaneous equation modeling. Considering these limitations, this paper does not claim to have offered exhaustive hypothesis testing. Rather, it has provided support to the existing studies and some additional insights into buyer influence on their supplier compliance-performance. Future research could address these points and to expand upon the inner-workings of the relationship channel.

\section{NOTES}

${ }^{1}$ For more information about the ILO monitoring program in Cambodia, please consult the website: http://www.betterfactories.org/

${ }^{2}$ The ILO monitoring program has been mostly financed by international donors, namely the US Department of Labor (USDOL), USAID, the Agence Française de Développement (AFD), as well as by the Cambodian Government, the Garment Manufacturers Association of Cambodia (GMAC) and international buyers. As the program seeks to be self-sustaining beyond 2010, the financing scheme is set to change.

${ }^{3}$ In fact, as one survey respondent was responsible for four branches, the actual survey size is 54. While the survey response is identical for the four branches, their factory characteristics and compliance data vary.

${ }^{4}$ A link to the web-based questionnaire was sent by email to 147 managers, of which 31 returned as delivery failures, and of which 18 responded (i.e. the response rate of 15.5 percent). Given the fast turnover of managers in the industry and the lack of internet use in some factories, the likelihood of 'deliberate refusal' is likely to be less than what the figure indicates. The response rate for collection through monitors is not available as the number of questionnaires distributed by monitors is not known. The response rate for the monitor channel is likely to be higher than the web-based one, but much lower than that of interviews.

${ }^{5}$ For explanation of each variable, please refer to the following section on measures and descriptive statistics.

${ }^{6}$ While checklist items under the category of labor relations exist, this category is not included in the analysis because the problem of clustering distorts true compliance performance.

${ }^{7} \mathrm{OSH}$ and welfare are grouped together as the latter is mainly concerned with health issues such as drinking water and toilets.

${ }^{8}$ The result based on the un-weighed composite is not substantially different from the output using the re-weighed composite, but the latter is more robust.

${ }^{9}$ Nonetheless, only 10 percent of them responded non-compliance has actually led to a cancellation of orders. This is because most suppliers rectify problems within a given time 
frame as demanded by buyers. Only when the problem is severe and recurrent do buyers terminate contracts.

${ }^{10}$ The Fair Labor Association (FLA), an American initiative, is the oldest and the best known brand-oriented MSI in labor regulation. Member companies are required to implement the FLA code of conduct, submit to un-announced monitoring by accredited auditors, and to commit to remediation and public reporting. Currently, 26 companies are participating, most of which are well-known apparel and sportswear brands as well as university affiliates. The Ethical Trading Initiative (ETI), a UK scheme, is geared toward learning and self-reporting rather than monitoring. The ETI encourages its member companies to implement its base code in their supply chains and require them to submit annual progress report on their code implementation. If progress is deemed unsatisfactory, members may be asked to resign. Currently, 50 companies are participating, most of which are large European brands and retailers.

${ }^{11}$ The coefficient of the interaction term (duration*MSI buyer) measures the difference in the slopes for MSI and non-MSI buyers while the coefficient of "Duration of relationship" measures the slope for non-MSI buyers. Therefore, the effect of an extra year of relationship (i.e. 2 years in this case) with an MSI buyer on non-compliance is the sum of coefficients for non-MSI and MSI buyers: 0.72-1.51= -0.79 .

${ }^{12}$ The coefficient of the interaction term (agents*MSI buyer) measures the difference in the slopes for MSI and non-MSI buyers while the coefficient of "Agents" measures the slope for non-MSI buyers. Therefore, the coefficient for the use of agents in the presence of MSI buyers is the sum of coefficients for non-MSI and MSI buyers: 9.75-8.36=1.39.

${ }^{13}$ Jiang (2009) succeeded in showing the statistical link between such norm-based relationships and compliance while he failed to show a significant link between market-based relationships and compliance.

\section{ACKNOLWEDEGEMENTS}

The author would like to thank Mr. Tuomo Poutiainen, Chief Technical Advisor of ILO Better Factories Cambodia (BFC) for his kind support and provision of data, BFC staff for various support and friendship, and survey respondents for their generosity. The author also thanks Rafael Gomez and an anonymous referee for helpful comments on previous drafts of this article. The author acknowledges partial financial support from the University of London Central Research Fund for the author's fieldwork in Cambodia. 


\section{REFERENCES}

Ashenfelter, O., \& Smith, R. S. (1979). Compliance with the minimum wage law. Journal of Political Economy, 87(2), 333-350.

Becker, G. (1983). A theory of competition among pressures groups for political influence. Quarterly Journal of Economics, 98(3), 371-400.

Bönte, W. (2008). Inter-firm trust in buyer-supplier relations: Are knowledge spillovers and geographical proximity relevant? Journal of Economic Behavior and Organization, $67,850-870$.

Bryson, A., Gomez, R., Kretschmer, T., \& Willman, P. (2007). The diffusion of workplace voice and high-commitment management practices in Britain, 1984-1998." Industrial and Corporate Change, 16(3), 395-426.

CCC (Clean Clothes Campaign). (2009). Cashing in: Giant retailers, purchasing practices, and working conditions in the garment industry. Amsterdam: CCC

http://www.cleanclothes.org/campaigns/1270-ccc-cashing-in-research-report-launched

Conroy, M. E. (2007). Branded: How the Certification Revolution is Transforming Global Corporations. Gabriola Island, BC: New Society Publishers.

Elliott, K. A., \& Freeman, R. B. (2003). Can Labor Standards Improve under Globalization? Washington, DC: Institute for International Economics

Erickson, C. L., \& Jacoby, S. M. (2003). The Effects of Employer Networks on Workplace Innovation and Training. Industrial and Labor Relations Review, 56 (2), 203-223.

Esbanshade, J. (2004). Monitoring Sweatshops: Workers, Consumers and the Global Apparel Industry. Philadelphia: Temple University.

Frenkel, S. J. (2001). Globalization, athletic footwear commodity chains and employment relations in China. Organization Studies, 22(4), 531-562.

Frenkel, S. J., \& Scott, D. (2002). Compliance, collaboration, and codes of labor practice: the ADIDAS connection. California Management Review, 45(1), 29-49.

Gundlach, G.T., Achrol, R. S., \& Mentzer, J. T. (1995). The structure of commitment in exchange. Journal of Marketing, 59(1), 78-92.

Hansen, M. H., \& Hurwitz, W.N. (2004). The problem of non response in sample surveys. The American Statistician, 58(4), 292-294

Hawkins, T., Wittman, C. M., \& Beyerlein, M. M. (2008). Antecedents and consequences of opportunism in buyer-supplier relations: Research synthesis and new frontiers. Industrial Marketing Management, 37, 895-909. 
Heide, J. B., \& John, G. (1992). Do norms matter in marketing relationships? Journal of Marketing, 56(4), 32-44.

Helper, S., MacDuffie, J. P., \& Sabel, C. (2000). Pragmatic collaborations: Advancing knowledge while controlling opportunism. Industrial and Corporate Change, 9 (3), 443-488.

Jenkins, R., Pearson, R. \& Seyfang, G. (2002). Corporate Responsibility and Labor Rights: Codes of Conduct in the Global Economy. London: Earthscan.

Jiang, G. (2009). Implementing supplier codes of conduct in global supply chains: Process explanations from theoretic and empirical perspectives. Journal of Business Ethics, 85, 77-92.

Joshi, A. W., \& Stump, R. L. (1999). Determinants of commitment and opportunism Integrating and extending insights from transaction cost analysis and relational exchange theory. Canadian Journal of Administrative Sciences, 16(4), 334-352.

Kolben, K. (2004). Trade, monitoring, and the ILO: Working to improve conditions in Cambodia's garment factories. New Haven, CT: Yale Human Rights \& Development Journal, 7, 79-107.

Locke, R. M., \& Romis, M. (2006). Beyond corporate codes of conduct: Work organization and labor standards in two Mexican garment factories. Corporate Social Responsibility Initiative Working Paper, no. 26. Cambridge, MA: John F. Kennedy School of Government, Harvard University.

Locke, R. M., Kochan, T., Romis, M., \& Qin, F. (2007). Beyond corporate codes of conduct: Work organization and labour standards at Nike's suppliers. International Labour Review, 146(1-2): 21-37.

Locke, R. M., Qin, F., \& Brause, A. (2007). Does monitoring improve labor standards? Lessons from Nike. Industrial and Labor Relations Review, 61(1): 3-31.

Macneil, I. R. (1980). The New Social Contract: An Inquiry into Modern Contractual Relations. New Haven, CT: Yale University Press.

Morgan, R. M., \& Hunt, S. D. (1994). The commitment-trust theory of relationship marketing. Journal of Marketing, 58, 20-38.

Nadvi, K., \& Waltring F. (2004). Making sense of global standards. In: H. Schmitz (eds.), Local Enterprises in the Global Economy: Issues of Governance and Upgrading. Northhampton, MA: Edward Elgar.

Oka, C. (2009). Can reputation conscious buyers improve working conditions? The case of Cambodia's garment sector. Best Paper Proceedings of the 2009 Academy of Management Meeting.

O'Rourke, D. (2006). Multi-stakeholder regulation: Privatizing or socializing global labor standards? World Development, 34(5), 899-918. 
Oxfam. (2004). Trading away our Rights: Women workers in global supply chains. Oxford: Oxfam. http://www.maketradefair.com/en/assets/english/taor.pdf

Play Fair. (2008). Clearing the hurdles: Steps to improving wages and working conditions in the global sportswear industry. http://www.playfair2008.org/docs/Clearing the_Hurdles.pdf

Polaski, S. (2006). Combining global and local forces: The case of labor rights in Cambodia. World Development, 34(5), 919-932.

Sako, M. (1992) Prices, Quality, and Trust: Inter-firm Relations in Britain and Japan. Cambridge: Cambridge University Press.

Sako, M., \& Helper, S. (1998). Determinants of trust in supplier relations: Evidence from the automotive industry in Japan and the United States. Journal of Economic Behavior and Organization, 34, 387-417.

Seidman, G. W. (2007). Beyond the Boycott: Labor Rights, Human Rights, and Transnational Activism. New York: Russell Sage Foundation.

Simon, H. A. (1957). Administrative behavior: a study of decision-making processes in administrative organization. New York: Macmillan.

Stigler, G. (1971). The theory of economic regulation. Bell Journal of Economics and Management Science, 2, 3-21.

USAID. (2007). Factory-level value chain analysis of Cambodia's apparel industry.

Vandaele, D., Rangarajan, D., Gemmel, P., \& Lievens, A. (2007). How to govern business services exchanges: Contractual and relational issues. International Journal of Management Reviews, 9 (3), 237-258.

Viscusi, W. K. (1979). The impact of occupational safety and health regulation. The Bell Journal of Economics, 10, 117-140.

Wathne, K. H. \& Heide, J. B. (2000). Opportunism in interfirm relationships: Forms, outcomes, and solutions. Journal of Marketing, 64, 36-51.

Weil, D. (2005). Public enforcement/private monitoring: Evaluating a new approach to regulating the minimum wage. Industrial and Labor Relations Journal, 58(2), 238257.

Weil, D., \& Mallo, C. (2007). Regulating labour standards via supply chains: Combining public/private interventions to improve workplace compliance. British Journal of Industrial Relations, 45(4), 791-814.

Williamson, O. E. (1975). Markets and Hierarchies: Analysis and Antitrust Implications. New York: Free Press. 
Williamson, O. E. (1985). The Economic Institutions of Capitalism: Firms, Markets, Relational Contracting, New York: Free Press.

Williamson, O. E. (1991). Comparative economic organization: The analysis of discrete structural alternatives. Administrative Science Quarterly, 36, 269-296.

Winter S.C., \& May, P. J. (2001). Motivation for compliance with environmental regulations. Journal of Policy Analysis and Management, 20(4), 675-698. 


\section{FIGURES AND TABLES}

Figure 1. Model of buyer influence on supplier compliance-performance

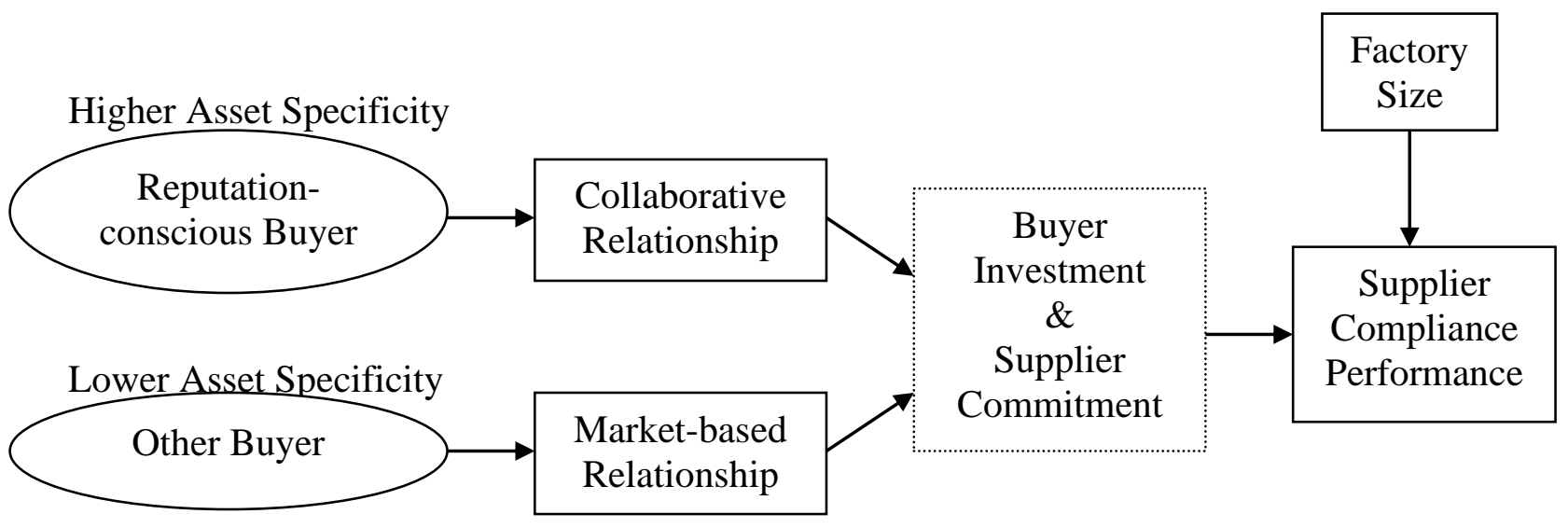

Table 1. The population and sample profiles

\begin{tabular}{|c|c|c|c|c|c|c|c|c|}
\hline & \multicolumn{2}{|c|}{ Non-compliance } & \multicolumn{2}{|c|}{ Factory Size } & \multicolumn{2}{|c|}{ Factory Age } & \multicolumn{2}{|c|}{ Presence of MSI buyer } \\
\hline & Population & Sample & Population & Sample & Population & Sample & Population & Sample \\
\hline Observation & 300 & 52 & 300 & 53 & 300 & 54 & 300 & 52 \\
\hline Mean & 20.0 & 17.8 & 1197.5 & 1420.3 & 5.4 & 5.9 & 0.4 & 0.4 \\
\hline S.D. & 12.4 & 9.7 & 1056.7 & 1086.6 & 2.3 & 2.4 & 0.7 & 0.5 \\
\hline
\end{tabular}


Table 2. Responses to the questionnaire on the channels of buyer influence

Percent Valid Missing

Deterrence

How many times does buyers' compliance staff visit your factory per year?

$50 \quad 1$

$0-2$ times

30

3-5 times

30

6-8 times

14

9-11 times

2

12-14 times

2

15 times or more

Your buyers have warned explicitly or implicitly about the risk of noncompliance leading to a cancellation of orders

$46 \quad 50 \quad 1$

Relationship

For how many years have you produced for your most important buyer?

$50 \quad 1$

0-2 years

3-4 years

28

5-6 years

26

7-8 years

10

9-10 years

6

10 years or more

Do you communicate directly with buyers or through vendors or agents?

Mostly directly with buyers

Mostly through vendors

Mostly through agents

Learning

Your buyers share technical knowledge

$51 \quad 0$

Yes, often times

33

Yes, sometimes

53

No, not really

14

Your buyers have been involved in determining the production system

26

510

Your buyers encourage training for workers/supervisors/managers

$50 \quad 1$

Yes, often times

Yes, sometimes 
Table 3. Correlation matrix of dependent, independent, and control variables

\begin{tabular}{|c|c|c|c|c|c|c|c|c|c|c|c|c|c|c|c|}
\hline & Variable & Mean & S.D. & 1 & 2 & 3 & 4 & 5 & 6 & 7 & 8 & 9 & 10 & 11 & 12 \\
\hline 1 & Non-compliance & 17.80 & 9.67 & & & & & & & & & & & & \\
\hline 2 & Visit frequency & 1.62 & 1.16 & -0.18 & & & & & & & & & & & \\
\hline 3 & Warning & 0.45 & 0.50 & -0.02 & -0.04 & & & & & & & & & & \\
\hline 4 & Duration & 3.07 & 1.60 & 0.08 & $-0.31 * *$ & 0.07 & & & & & & & & & \\
\hline 5 & Agents & 0.31 & 0.46 & $0.39 * * *$ & 0.00 & 0.02 & -0.01 & & & & & & & & \\
\hline 6 & Share knowledge & 0.32 & 0.47 & -0.14 & 0.01 & $0.35^{* *}$ & -0.03 & 0.08 & & & & & & & \\
\hline 7 & Production system & 0.25 & 0.44 & -0.24 & 0.05 & 0.11 & -0.04 & -0.09 & $0.29 * *$ & & & & & & \\
\hline 8 & Encourage training & 0.30 & 0.43 & -0.20 & 0.07 & -0.08 & -0.02 & -0.12 & 0.14 & 0.05 & & & & & \\
\hline 9 & MSI buyer & 0.44 & 0.50 & $-0.36 * * *$ & 0.26 & -0.23 & -0.04 & $-0.34 * *$ & 0.04 & 0.06 & $0.53 * * *$ & & & & \\
\hline 10 & Factory size & 7.01 & 0.70 & $-0.38 * * *$ & 0.14 & 0.08 & 0.02 & -0.22 & $0.31 * *$ & 0.14 & $0.40 * * *$ & $0.61 * * *$ & & & \\
\hline 11 & Factory age & 5.94 & 2.40 & -0.01 & 0.10 & -0.18 & 0.21 & -0.16 & -0.19 & 0.04 & -0.13 & 0.17 & 0.18 & & \\
\hline 12 & FOB & 0.82 & 0.40 & -0.17 & 0.01 & 0.05 & 0.14 & -0.21 & 0.12 & $-0.29 * *$ & 0.24 & $0.31 * *$ & 0.25 & 0.05 & \\
\hline 13 & Independent & 0.20 & 0.40 & 0.21 & -0.01 & -0.05 & -0.14 & $0.32 * *$ & 0.09 & 0.17 & -0.04 & -0.20 & -0.23 & -0.15 & $-0.39 * * *$ \\
\hline
\end{tabular}


Table 4. Deterrence model results

\begin{tabular}{|c|c|c|c|c|}
\hline \multirow{2}{*}{$\begin{array}{l}\text { Variable } \\
\text { Visit frequency }\end{array}$} & \multicolumn{2}{|c|}{ Model 1} & \multicolumn{2}{|c|}{ Model 2} \\
\hline & -0.91 & $(1.15)$ & -1.07 & $(1.72)$ \\
\hline Warning & -2.41 & $(2.67)$ & -3.13 & $(3.56)$ \\
\hline MSI buyer & $-7.01 * *$ & $(2.78)$ & -5.07 & $(5.45)$ \\
\hline Visit frequency*MSI buye & & & -1.47 & $(2.40)$ \\
\hline Warning*MSI buyer & & & 0.95 & $(5.69)$ \\
\hline Constant & $23.45 * * * *$ & $(2.75)$ & $22.74 * * * *$ & $(3.27)$ \\
\hline Observation & 50 & & 50 & \\
\hline R-squared & 0.16 & & 0.16 & \\
\hline F-value & $2.84 * *$ & 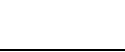 & 1.73 & \\
\hline
\end{tabular}

Table 5. Relationship model results

\begin{tabular}{|c|c|c|c|c|}
\hline \multirow{2}{*}{$\begin{array}{l}\text { Variable } \\
\text { Duration of relationship }\end{array}$} & \multicolumn{2}{|c|}{ Model 3} & \multicolumn{2}{|c|}{ Model 4} \\
\hline & 0.41 & $(0.76)$ & 0.72 & $(0.81)$ \\
\hline Agents & $5.71 * *$ & $(2.82)$ & $9.75 * * *$ & $(3.01)$ \\
\hline MSI buyer & $-5.56 * *$ & (2.63) & 1.08 & $(2.98)$ \\
\hline Duration*MSI buyer & & & $-1.51^{*}$ & $(0.79)$ \\
\hline Agents*MSI buyer & & & -8.36 & $(5.64)$ \\
\hline Constant & $17.44 * * * *$ & $(3.21)$ & $13.72 * * * *$ & $(3.07)$ \\
\hline Observation & 51 & & 49 & \\
\hline R-squared & 0.22 & & 0.36 & \\
\hline F-value & $4.57 * * *$ & & $4.87 * * *$ & \\
\hline
\end{tabular}


Table 6. Learning model results

\begin{tabular}{|c|c|c|c|c|}
\hline Variable & \multicolumn{2}{|c|}{ Model 5} & \multicolumn{2}{|c|}{ Model 6} \\
\hline Share knowledge & -1.65 & $(2.96)$ & -3.81 & $(4.56)$ \\
\hline Production system & -4.51 & $(3.20)$ & -3.76 & $(4.82)$ \\
\hline Encourage training & 0.19 & $(3.25)$ & 3.19 & $(6.00)$ \\
\hline MSI buyer & $-6.44 * *$ & $(3.05)$ & -6.09 & $(4.25)$ \\
\hline Knowledge*MSI buyer & & & 3.58 & $(6.20)$ \\
\hline System*MSI buyer & & & -1.20 & $(6.66)$ \\
\hline Training*MSI buyer & & & -4.72 & $(7.25)$ \\
\hline Constant & $22.17 * * * *$ & $(1.97)$ & $22.27 * * * *$ & $(2.18)$ \\
\hline Observation & 51 & & 51 & \\
\hline R-squared & 0.18 & & 0.19 & \\
\hline F-value & $2.55^{*}$ & & 1.47 & \\
\hline
\end{tabular}


Table 7. Main regression results with significant variables and added controls

\begin{tabular}{|c|c|c|c|c|}
\hline Variable & \multicolumn{2}{|c|}{ Model 7} & \multicolumn{2}{|c|}{ Model 8} \\
\hline Duration of relationship & 0.52 & $(0.83)$ & & \\
\hline Agents & $10.09 * * *$ & $(3.24)$ & $6.54 * *$ & $(2.66)$ \\
\hline MSI buyer & 3.32 & $(3.31)$ & & \\
\hline Duration*MSI buyer & $-1.33 *$ & $(0.79)$ & & \\
\hline Agents*MSI buyer & -7.92 & $(5.73)$ & & \\
\hline Factory size & $-4.37 * *$ & $(2.16)$ & $-4.28 * *$ & $(1.80)$ \\
\hline Factory age & 0.73 & $(0.55)$ & & \\
\hline FOB & 0.34 & $(3.14)$ & & \\
\hline Independent & -1.28 & $(3.23)$ & & \\
\hline Constant & $39.34 * *$ & (14.96) & $45.85 * * * *$ & (12.94) \\
\hline Observation & 49 & & 52 & \\
\hline R-square & 0.44 & & 0.24 & \\
\hline F-value & $3.43 * * *$ & & $7.74 * * *$ & \\
\hline
\end{tabular}

